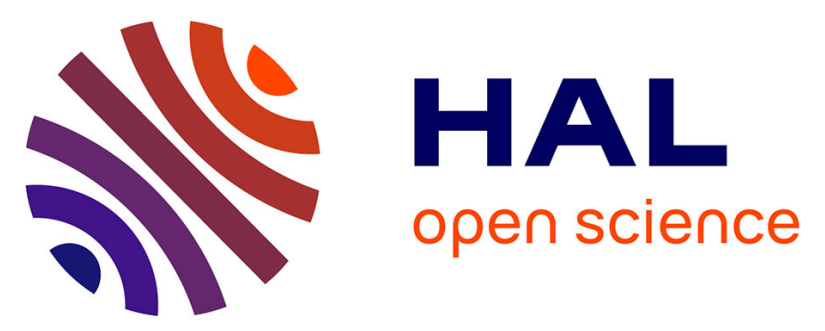

\title{
Bulk, surface properties and water uptake mechanisms of salt/acid amorphous composite systems
}

\author{
Stefano Bianco, Frederic Tewes, Lidia Tajber, Vincent Caron, Owen I.
}

Corrigan, Anne Marie Healy

\section{To cite this version:}

Stefano Bianco, Frederic Tewes, Lidia Tajber, Vincent Caron, Owen I. Corrigan, et al.. Bulk, surface properties and water uptake mechanisms of salt/acid amorphous composite systems. International Journal of Pharmaceutics, 2013, 456 (1), pp.143-152. 10.1016/j.ijpharm.2013.07.076 . inserm01102838

\section{HAL Id: inserm-01102838 https://www.hal.inserm.fr/inserm-01102838}

Submitted on 13 Jan 2015

HAL is a multi-disciplinary open access archive for the deposit and dissemination of scientific research documents, whether they are published or not. The documents may come from teaching and research institutions in France or abroad, or from public or private research centers.
L'archive ouverte pluridisciplinaire HAL, est destinée au dépôt et à la diffusion de documents scientifiques de niveau recherche, publiés ou non, émanant des établissements d'enseignement et de recherche français ou étrangers, des laboratoires publics ou privés. 
Amorphous material hygroscopicity

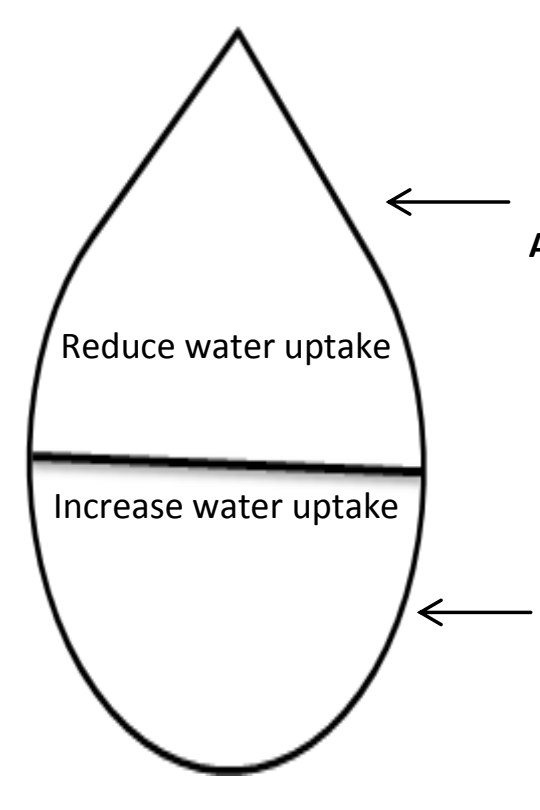

Optimum

Ratio

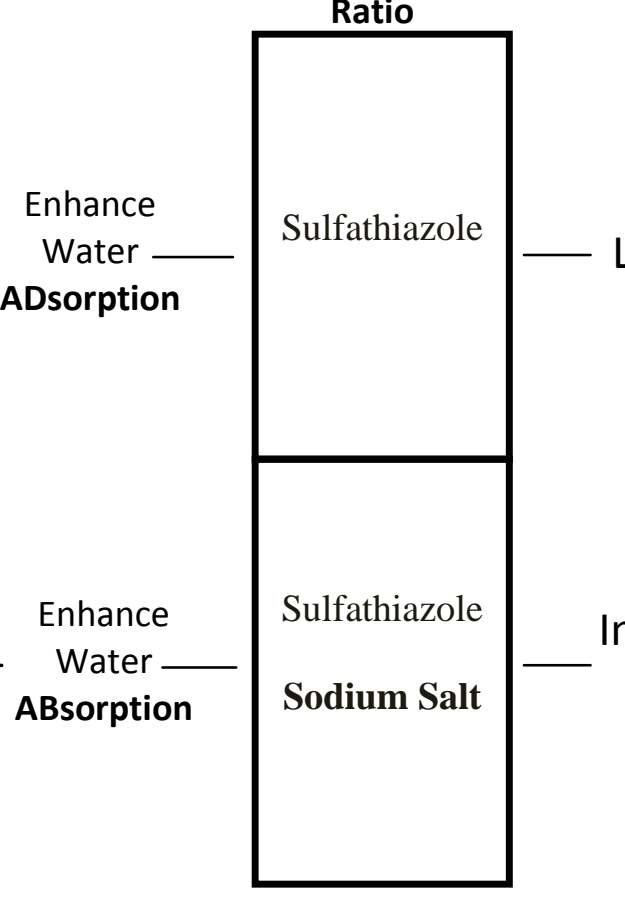

Amorphous material

crystallisation

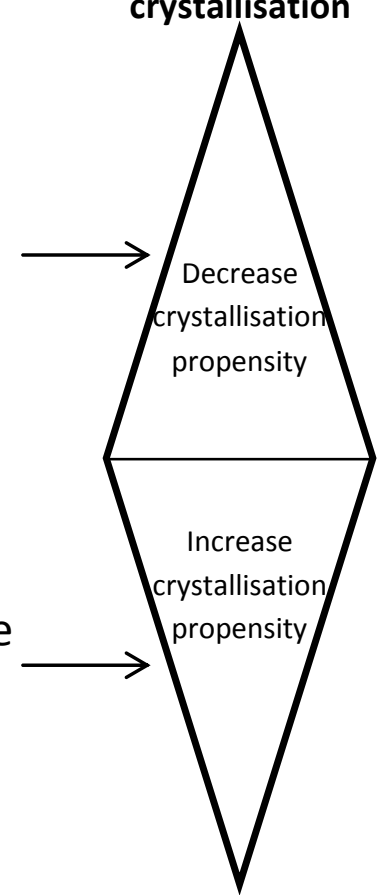


1 Bulk, surface properties and water uptake mechanisms of salt/acid

2 amorphous composite systems

4 Stefano Bianco ${ }^{1}$, Frederic Tewes ${ }^{1,2}$, Lidia Tajber ${ }^{1}$, Vincent Caron $^{1}$, Owen I. Corrigan ${ }^{1}$ and Anne

$5 \quad$ Marie Healy ${ }^{1, *}$

6

7 1- School of Pharmacy and Pharmaceutical Sciences, Trinity College Dublin, College Green, Dublin 2, Ireland.

9

2- INSERM U 1070, Pôle Biologie-Santé, Faculté de Médecine \& Pharmacie, Université de Poitiers, 1 rue Georges Bonnet, 86000 Poitiers, France

12

$13 *$ To whom correspondence should be sent. Ph.: 003531896 1444, e-mail: healyam@tcd.ie 


\section{Abstract}

16 Developing amorphous pharmaceuticals can be desirable due to advantageous biopharmaceutical 17 properties. Low glass transition temperature ( $\mathrm{Tg}$ ) amorphous drugs can be protected from 18 crystallisation by mixing with high $\mathrm{Tg}$ excipients, such as polymers, or with salt forms. 19 However, both polymers and salts can enhance the water uptake. The aim of this study was to 20 formulate physico-chemically stable amorphous materials, by co-processing different 21 proportions of sulfathiazole and its sodium salt to produce an optimum ratio, characterised by the 22 best physical stability and lowest hygroscopicity. Both sulfathiazole and salt amorphised upon 23 spray drying. At room temperature, sulfathiazole crystallised within 1 hour at $<5 \%$ relative 24 humidity while the salt deliquesced when exposed to ambient humidity conditions. In the case of 25 composite systems, FTIR spectroscopy, thermal and surface analysis suggested interactions with 26 an acid:salt stoichiometry of 1:2. Increasing proportions of salt raised the $\mathrm{Tg}$, enhancing the 27 storage stability, however this was opposed by an enhanced hygroscopicity. The water uptake 28 mechanism within the different amorphous systems, analysed by fitting the water sorption 29 isotherms with the Young and Nelson equation, was dependent on the ratio employed, with the salt and the acid facilitating absorption and adsorption, respectively. Tuning the properties of amorphous salt/acid composites by optimising the ratio appears potentially promising to improve

32 the physical stability of amorphous formulations. 


\section{Introduction}

35 The requirement to improve the bioavailability of poorly soluble active pharmaceutical ingredients (API) has resulted in a growing use of processes such as milling and spray drying,

37 which reduce particle dimensions and increase specific surface area. It is well established that 38 partial or full amorphisation of an API can occur as a result of these processes and that changes in the solid state nature can alter the physicochemical and biopharmaceutical properties (Caron et al., 2011; Tajber et al., 2005; Yu, 2001). Amorphous materials are structurally disorganised and have different bulk and surface properties compared to the corresponding crystalline materials.

42 They typically display higher surface free energy (Newell et al., 2001b), higher hygroscopicity 43 (Newman et al., 2008), greater solubility and a higher dissolution rate (Tajber et al., 2005). Although these properties are relevant from a pharmaceutical development perspective, the full 45 exploitation of amorphous drugs and formulations cannot always be achieved, mainly due to low 46 physical and chemical stability (Caron et al., 2011; Yu, 2001). Therefore a thorough 47 understanding of the properties of the amorphous state is required to develop new strategies to physico-chemically stabilise amorphous compounds.

Previously, we studied several physicochemical properties of sulfathiazole (ST) and sulfathiazole sodium (STNa), which solidify into unstable amorphous materials on spray drying (Bianco et al.,

51 2012). The acid rapidly crystallised regardless of the relative humidity (RH) conditions. The

52 crystallisation of amorphous solids can be promoted by heat and therefore these materials usually 53 require storage at temperatures well below their glass transition temperature ( $\mathrm{Tg}$ ) (Caron et al., 54 2011; Hancock et al., 1995; Yu, 2001). Considerable effort has been made to address this 55 problem, either by co-processing heat labile amorphous drugs with high Tg excipients (Caron et 56 al., 2011) or by using amorphous salt forms of these compounds (Tong et al., 2002; Tong and 
57 Zografi, 1999). In many cases a shift of the Tg to higher temperature has been achieved, which is

58 potentially a good strategy to stabilise amorphous formulations. However this is not always

59 sufficient and other influential factors affecting stability must also be considered. For instance,

60 amorphous STNa was characterised by a $60^{\circ} \mathrm{C}$ increase in $\mathrm{Tg}$ compared to ST and was

61 physically stable when stored under desiccated conditions. Nevertheless, it deliquesced when

62 exposed to ambient RH conditions (Bianco et al., 2012).

63 Deliquescence together with adsorption, capillary condensation, hydrate formation and

64 absorption, is one of the known mechanisms of solid-water interactions (Airaksinen et al., 2005;

65 Hiatt et al., 2011). It is a first order phase transition that happens when a water soluble solid

66 generates a saturated solution by dissolving into the water sorbed from the environment at a

67 specific relative humidity $\left(\mathrm{RH}_{0}\right)$ characteristic for that solid. Due to high void space and enlarged

68 free volume relative to the crystalline state, amorphous substances absorb water below RHo and

69 undergo deliquescence at a lower RH compared to their crystalline counterparts (Mikhailov et

70 al., 2009). The amount of water absorbed into amorphous materials is proportional to the

71 volume/weight of the amorphous solid and high absorption and retention of water can enhance

72 chemical reactions which may lead to product degradation (Hancock and Shamblin, 1998).

73 Furthermore, sorbed water as well as heat can promote the crystallisation of amorphous materials

74 (Baird and Taylor, 2012; Burnett et al., 2006).

75 Therefore strategies to stabilise amorphous materials should aim at both increasing the $\mathrm{Tg}$ and 76 protecting the amorphous system from water uptake. Co-formulation of a deliquescent salt form

77 (sodium ascorbate) with excipients (maltodextrins) was seen to reduce the moisture sorption and 78 enhance the physical stability of this salt (Hiatt et al., 2011). It was also observed that the 
79 production of molecular dispersions of indomethacin and indomethacin sodium via evaporation 80 under vacuum influenced the physicochemical characteristics of each species (Tong and Zografi, $812001)$.

82 The aim of the current research was to improve the physical stability of amorphous ST/STNa 83 mix in terms of crystallisation and deliquescence by adjusting the salt/acid ratio in the composite 84 systems.

85 


\section{$87 \quad 2.1$ Materials}

88 Sulfathiazole (ST) form III and sulfathiazole sodium (STNa) anhydrous were purchased from

89 Sigma Ireland. Ethanol $(99.5 \% \mathrm{v} / \mathrm{v})$ was purchased from Corcoran Chemicals (Ireland) and 90 deionised water produced by a Millipore Elix Advantage water purification system.

\section{$91 \quad$ 2.2 Spray drying}

92 Spray dried powders were obtained using a Buchi B-290 Mini Spray dryer (Buchi

93 Laboratoriums-Technik AG, Flawil, Switzerland) operating in an open cycle mode configuration

94 using air as the drying gas. $0.5 \% \mathrm{w} / \mathrm{v}$ feed solutions were prepared by dissolving the APIs

95 (Table 1) in a mixture of ethanol and deionised water at a v/v ratio of 9:1, as previously

96 described (Bianco et al., 2012). Spray drying of ST and ST-STNa systems was performed using

97 the following parameters: gas flow of $40 \mathrm{~mm}(473 \mathrm{~L} / \mathrm{hr})$; aspirator rate of $100 \%$ and feed flow

98 rate of $30 \%(8 \mathrm{ml} / \mathrm{min})$. The inlet temperature for the mixtures was adapted to the amount of salt

99 employed in the system ranging from 85 to $90^{\circ} \mathrm{C}$ and reported in table 1 . The salt alone was

100 instead spray dried with an inlet of $160^{\circ} \mathrm{C}$ so as to produce a dry powder (Bianco et al., 2012).

101 Samples were transferred to Amebis humidity devices (Amebis Ltd., Ireland) at $<5 \% \mathrm{RH}$

102 (Bianco et al., 2012) and stored in a cold room at $5 \pm 1^{\circ} \mathrm{C}$ immediately after spray drying. 
Table 1: Spray drying parameters for ST: STNa systems. (An inlet temperature higher than $85^{\circ} \mathrm{C}$ for ST 9:1 resulted in partially crystalline materials. For the other systems an inlet temperature lower than $90^{\circ} \mathrm{C}$ resulted in wet powders).

\begin{tabular}{|c|c|c|}
\hline $\begin{array}{c}\text { ST: STNa } \\
\text { Weight ratio } \\
(\mathrm{w} / \mathrm{w})\end{array}$ & Code & Inlet $\left({ }^{\circ} \mathrm{C}\right)$ \\
\hline $9: 1$ & ST $9: 1$ & 85 \\
\hline $8: 2$ & ST $8: 2$ & 90 \\
\hline $3: 1$ & ST $3: 1$ & 90 \\
\hline $3: 2$ & ST $6: 4$ & 90 \\
\hline $1: 1$ & ST $1: 1$ & 90 \\
\hline $4: 6$ & ST $4: 6$ & 90 \\
\hline $1: 3$ & ST $1: 3$ & 90 \\
\hline $15: 85$ & ST $15: 85$ & 90 \\
\hline
\end{tabular}

\subsection{Thermal analysis}

Differential scanning calorimetry (DSC) runs were conducted on a Mettler Toledo DSC $821^{\mathrm{e}}$ (Mettler Toledo Ltd., Greifensee, Switzerland) using nitrogen as a purge gas. Samples (3-7 mg) were placed in closed aluminium pans with three vent holes and were heated at a scanning rate of $10{ }^{\circ} \mathrm{C} / \mathrm{min}$ from $25^{\circ} \mathrm{C}$ to $280^{\circ} \mathrm{C}$. The thermograms $(\mathrm{n} \geq 2)$ were analysed by Mettler Toledo STAR $^{\mathrm{e}}$ software.

Modulated temperature DSC (MTDSC) scans were recorded on a QA-200 TA instruments (TA instruments, United Kingdom) calorimeter using nitrogen as a purge gas. Weighed samples (1.5$3.5 \mathrm{mg}, \mathrm{n} \geq 2$ ) were sealed in closed aluminium pans with one pin-hole. The method selected was similar to that previously reported by (Caron et al., 2011). A scanning rate of $1^{\circ} \mathrm{C} / \mathrm{min}$, amplitude of modulation of $1^{\circ} \mathrm{C}$ and modulation frequency of $1 / 60 \mathrm{~Hz}$ were employed for all the experiments. The temperature range was from $5^{\circ} \mathrm{C}$ to $200^{\circ} \mathrm{C}$. 


\subsection{Powder X-ray diffraction (XRD)}

121 X-ray powder diffraction measurements were conducted using a low background silicon sample 122 holder and a Rigaku Miniflex II desktop X-ray diffractometer (Rigaku, Tokio, Japan) as 123 previously described (Caron et al., 2011; Tewes et al., 2013). The samples $(\mathrm{n} \geq 2)$ were scanned 124 over a range of $5-40^{\circ}$ in $2 \theta$ scale using a step size of $0.05^{\circ} /$ s. The X-ray source was a $\mathrm{Cu} \mathrm{K} \alpha$ 125 radiation $(\lambda=1.542 \AA)$ and the diffractometer was operated with a voltage of $30 \mathrm{kV}$ and a current 126 of $15 \mathrm{~mA}$.

\subsection{Attenuated total reflection Fourier transform infra-red spectroscopy (ATR-FTIR)}

128 Infrared spectra were produced using a PerkinElmer Spectrum one FT-IR Spectrometer and 129 evaluated using Spectrum v5.0.1 software as previously described (Grossjohann et al., 2012; 130 Tewes et al., 2011). An average of 6 scans with a resolution of $4 \mathrm{~cm}^{-1}$ over a wavenumber region 131 of $4000-650 \mathrm{~cm}^{-1}$ was used for each sample. All spectra were baseline corrected. The spectrum of 132 pure STNa was subtracted from the mixture spectra, considering their molar ratio.

\subsection{Scanning electron microscopy (SEM)}

134 SEM micrographs of samples were taken using a Tescan Mira XMU (Brno, Czech Republic) 135 SEM. The dry powder samples were fixed on aluminium stubs with double-sided adhesive tape 136 and a $10 \mathrm{~nm}$-thick gold film was sputter coated on the samples before visualisation. Primary 137 electrons were accelerated under a voltage of $5 \mathrm{kV}$. Images were formed from the collection of 138 secondary electrons. 


\subsection{Water sorption analysis}

141 Water sorption behaviour of samples was determined using a DVS Advantage 1 apparatus (DVS 142 Surface Measurement Systems, London, UK), as previously described (Tewes et al., 2010). 143 Samples placed in a microbalance were exposed to three cycles of $\mathrm{RH}(0-90-0 \%)$ at $25^{\circ} \mathrm{C}$, with 144 the following steps: 3, 6, 10 and then every 10\% $\mathrm{RH}(\mathrm{n}=3)$. Water sorption isotherms were 145 calculated using the equilibrated mass $(\mathrm{dm} / \mathrm{dt} \leq 0.002 \mathrm{mg} / \mathrm{min}$ for $10 \mathrm{~min})$ recorded at the end of 146 each stage and expressed as a percentage of the dry sample mass. The Young-Nelson equations 147 were used to fit experimental equilibrium sorption and desorption data of the isotherms (Tewes et 148 al., 2010):

$149 M_{s}=A(\beta+\theta)+B \theta R H$

$150 \quad M_{d}=A(\beta+\theta)+B \theta R H_{\max }$

151 where $M_{s}$ and $M_{d}$ are, respectively, the mass percentage of water contents of the system at 152 equilibrium for each \% RH during sorption and desorption. $A$ and $B$ are constants characteristic of 153 each system and defined by the following equations:

$154 \quad A=\delta w \operatorname{Vol}_{\mathrm{M}} /(\mathrm{Wm})$

$155 \quad B=\delta w \operatorname{Vol}_{\mathrm{A}} /(\mathrm{Wm})$

156 where $\delta w$ is the density of the water, Volm and $\mathrm{Vol}_{\mathrm{A}}$ are respectively the adsorbed and absorbed 157 water volumes and $\mathrm{Wm}$ is the weight of the dry material.

158 In this model, $\theta$ is the fraction of the surface covered by at least one layer of water molecules. It 159 is defined as follows, with $E$ a constant depending on the material. 
$161 \beta$ is defined by the following equation:

$162 \beta=-E \times R H /(E-R H \times(E-1))+E^{2} /(E-1) \times \ln [E-R H(E-1) / E]-(E+1) \times \ln (1-R H)$

163 Thus, $A \theta$ is the mass of water in a complete adsorbed monolayer expressed as a percentage of the 164 dry mass of the sample. $A(\beta+\theta)$ is the total amount of adsorbed water, and $A \beta$ is the mass of 165 water which is adsorbed beyond the mass of the monolayer (i.e., in multilayer or cluster 166 adsorption). $B$ is the mass of absorbed water at $100 \%$ of $\mathrm{RH}$, and, hence, $B \theta \mathrm{RH}$ is the mass of 167 absorbed water when the water coverage is $\theta$ for a given \%RH. According to the model 168 characteristics, from the estimated values of $A, B$, and $E$, the corresponding profiles of water 169 adsorbed in monolayer $(A \theta)$, multilayer $(A \beta)$ and absorbed $(B \theta R H)$ were obtained.

\subsection{Surface free energy measurement}

171 Surface free energy measurements were carried out using inverse gas chromatography (iGC) 172 (SMS Ltd., London, UK), as described previously (Tewes et al., 2011). Powders were packed 173 into silanised glass columns $(300 \mathrm{~mm} \times 3 \mathrm{~mm})$. The columns were pre-treated for $1 \mathrm{~h}$ at $30^{\circ} \mathrm{C}$ and $1740 \% \mathrm{RH}$ to remove any physisorbed molecules. Then, $250 \mu \mathrm{L}$ of the elution mixture (probe 175 vapour and helium) was injected into the carrier gas (helium) flow. All injections of probe 176 vapours were performed at $0.03 \% \mathrm{v} / \mathrm{v}$ of the saturated probe vapour. A flame ionization detector 177 was used to monitor the elution of probe vapours. Measurements were performed at 0, 10 and $17820 \%$ of $\mathrm{RH}$ and $30^{\circ} \mathrm{C},(\mathrm{n}=2)$. In acid-base theory, the total surface free energy of a solid $\left(\gamma_{s}^{T}\right)$ has

1792 main components: a dispersive contribution $\left(\gamma_{s}^{d}\right)$ and a specific or acid-base contribution $\left(\gamma_{s}^{A B}\right)$, 180 which are independent and additive, according to Eq. (7).

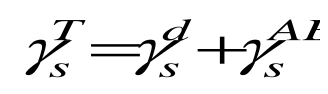


182 In order to calculate $\gamma_{s}^{d}$ of the powders, alkane probes with a known dispersive contribution $\left(\gamma_{p}{ }^{d}\right)$ 183 and a nil specific contribution $\left(\gamma_{p}{ }^{A B}\right)$ were used. Methane was used as inert reference to determine 184 the dead volume of the system. At this low $\%$ of saturation $(0.03 \% \mathrm{v} / \mathrm{v})$, iGC was used in infinite 185 dilution conditions and $\gamma_{s}{ }^{d}$ was calculated using the method developed by Schultz et al. (Schultz 186 et al., 1987). $\gamma_{s}^{A B}$ was obtained indirectly via the measurement of the specific free energy of 187 adsoption $\left(\Delta G^{S P}\right)$ of 2 monopolar probes and by using the acid-base theories developed by Van 188 Oss et al. (vOCG) (Van Oss et al., 1988). In the vOCG theories, $\gamma_{s}^{A B}$ is subdivided into two non189 additive parameters $\gamma_{s}{ }^{+}$and $\gamma_{s}^{-}$related according to Eq. (8), representing the electron acceptor 190 (acid) and donor (base) properties, respectively.

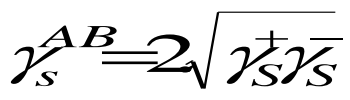

192 By using ethyl acetate $\left(\gamma_{p}^{-}=475.67, \gamma_{p}{ }^{+}=0 \mathrm{~mJ} / \mathrm{m}^{2}\right.$, at $\left.30^{\circ} \mathrm{C}\right)$ as the base probe and 193 dichloromethane $\left(\gamma_{p}{ }^{-}=0, \gamma_{p}{ }^{+}=124.58 \mathrm{~mJ} / \mathrm{m}^{2}\right.$, at $\left.30^{\circ} \mathrm{C}\right)$ as the acid probe with the acid and base 194 component values calculated based on the Della Volpe and Siboni scale (Della Volpe and Siboni, 195 1997), $\gamma_{s}{ }^{+}$and $\gamma_{s}^{-}$of the surface of the powders were calculated. Polarity index $\left(\gamma_{S}^{A B} / \gamma_{S}^{d}\right)$ was 196 then calculated.

197 Additionally the spreading coefficient $\left(S_{S L}\right)$ was calculated using the dispersive contribution $\left(\gamma_{s}{ }^{d}\right)$ 198 and the acid-base contribution $\left(\gamma_{s}{ }^{+}\right.$and $\left.\gamma_{s}^{-}\right)$of the total surface free energy of the solid and of the 199 liquid (water) by the following equation.

$$
S_{S L}=2 \cdot \sqrt{\gamma_{S}^{d} \gamma_{L}^{d}}+2 \cdot \sqrt{\gamma_{S}^{+} \gamma_{L}^{-}}+2 \cdot \sqrt{\gamma_{S}^{-} \gamma_{L}^{+}}-4 \cdot \sqrt{\gamma_{L}^{+} \gamma_{L}^{-}}-2 \gamma_{L}^{d}
$$


201 Where $\gamma_{L}{ }^{d}, \gamma_{L}^{+}$and $\gamma_{L}^{-}$are respectively the dispersive contribution $\left(\gamma_{L}{ }^{d}\right)$ and the acid-base 202 contribution $\left(\gamma_{L}{ }^{+}\right.$and $\left.\gamma_{L}{ }^{-}\right)$of the total surface free energy of the of the liquid (water) (Zdziennicka 203 and Jańczuk, 2010).

\section{$204 \quad 2.9$ Density measurements}

205 The density of spray dried ST and STNa was measured by an Accupyc 1330 Pycnometer 206 (Micromeritics $®)$ using helium (99.995\% purity) to determine the volume of the sample. 207 Samples were dried prior to measurement for $24 \mathrm{~h}$ in a Gallenkamp vacuum oven operating at 208600 mbar and $25^{\circ} \mathrm{C}$.

$209 \quad 2.10$ Statistical analysis

210 Data were statistically evaluated by a two-way analysis of variance (ANOVA) test with 211 Bonferroni test as post-hoc test. Significance level was $\alpha<0.05$. 


\section{Results and discussion}

\subsection{PXRD, DSC and FTIR analysis of spray dried systems}

Previous experiments showed that ST and STNa solidified into amorphous materials on spray drying. However, both spray dried substances were physically unstable. Amorphous ST started to crystallise to polymorph I $\sim 30$ minutes after the end of the spray drying process regardless of the temperature and RH of storage. In contrast, spray dried STNa remained amorphous when stored for over a year in desiccated conditions at $5 \pm 1^{\circ} \mathrm{C}$. Nevertheless, amorphous STNa rapidly deliquesced at ambient conditions $\left(18-22^{\circ} \mathrm{C}\right.$ and $\left.40-80 \% \mathrm{RH}\right)$ (Bianco et al., 2012).

All ST: STNa spray dried composites presented a diffuse halo pattern, characteristic of XRD amorphous materials (Fig. 1).

Figure 1: PXRD patterns of: (a) unprocessed ST (form III); b) spray dried ST; c) spray dried ST 9:1; d) spray dried ST 3:1; e) spray dried ST 1:1; f) spray dried ST 1:3; g) spray dried STNa; h) unprocessed STNa.

The ST: STNa ratio employed and the storage conditions influenced the physical stability of the processed powders. For example, in desiccated conditions at $5^{\circ} \mathrm{C}$, by using just $10 \%$ w/w of the salt form, the resulting composite remained amorphous for $\sim 2$ months as observed by PXRD. Higher amounts of salt in the composites increased the stability by up to 5 months for ST 3:1 and by six months for ST 1:1 and ST 1:3.

SEM images showed that ST: STNa composite samples were homogeneous and consisted of spherical smooth particles with surface indentations for systems comprising up to $50 \%$ w/w STNa (Fig. 2a-b-c). In contrast, no discrete particles were detected by SEM for a higher STNa content. Both ST 1:3 (Fig. 2d) and STNa deliquesced, indicating a higher affinity of these two samples for water compared to the other systems. 
Figure 2: SEM micrographs of: a) spray dried ST 9:1; b) spray dried ST 3:1; c) spray dried ST1:1; d) spray dried ST1:3.

Previously reported thermal analysis of pure spray dried ST showed an exotherm of crystallization at $79 \pm 0.5^{\circ} \mathrm{C}$ followed by an endotherm of melting at $201 \pm 0.5^{\circ} \mathrm{C}$ while the amorphous salt crystallised above $160^{\circ} \mathrm{C}$ and melted at $268 \pm 0.2^{\circ} \mathrm{C}$ (Bianco et al., 2012). Spray dried ST 9:1, ST 8:2, ST 3:1 and ST 15:85 (Fig. 3) presented one endothermic event of melting. These composites also showed one exotherm of crystallisation with onset ranging between those of the pure materials. In contrast ST 6:4, ST 1:1, ST 4:6 and ST 1:3 did not show either exothermic or melting peaks on the thermograms. The inhibition of crystallisation upon heating (at 1 or $10^{\circ} \mathrm{C} / \mathrm{min}$ ) for these mixtures could be due to the development of molecular interactions between ST: STNa for these specific ST: STNa ratios (Tong and Zografi, 2001).

Figure 3: Heat flow thermograms of: (a) unprocessed ST (form III); b) spray dried ST; c) spray dried ST 9:1; d) spray dried ST 3:1; e) spray dried ST 1:1; f) spray dried ST 1:3; g) spray dried ST 15:85 h) spray dried STNa; i) unprocessed STNa.

The glass transition temperature (Tg) for pure ST and STNa were previously found to be $\sim 59^{\circ} \mathrm{C}$ and $\sim 120^{\circ} \mathrm{C}$, respectively (Bianco et al., 2012). To determine the Tgs of the various composites and distinguish between thermal events which could happen simultaneously upon heating, MTDSC was employed in this work. All reversing heat flow thermograms recorded for the different spray dried systems showed a single $\mathrm{Tg}$, with values between those of the pure materials and increasing with the STNa content. According to several authors (Bosma et al., 1988; Caron et al., 2011; Tong and Zografi, 2001) the detection of a single Tg is indicative of homogeneous amorphous phases (molecular dispersions). Therefore, thermal analysis revealed that the increase of physical stability was due to the introduction of STNa in the mixture which shifted the Tgs to higher temperatures. Measured Tgs and Tg values calculated using the Gordon 
Taylor with Simha-Boyer rule (GT_- equation 10) (Caron et al., 2011; Tajber et al., 2005) were plotted versus STNa weight fraction (Fig. 4).

$$
T_{g}(\text { mix })=\frac{w_{1} T_{g 1}+K_{G T} w_{2} T_{g 2}}{w_{1}+K_{G T} w_{2}} \underline{\text { where }} K_{G T}=\frac{d_{1} T_{g 1}}{d_{2} T_{g 2}}
$$

$\underline{T}_{g}, \underline{w}$ and $d$ are the glass transition temperature in degrees Kelvin, the weight fraction, and density of the subscripts 1 - first component, 2 - second component, respectively.

The true densities for the pure amorphous components of $1.52 \mathrm{~g} / \mathrm{cm}^{3}$ and $1.57 \mathrm{~g} / \mathrm{cm}^{3}$ for ST and STNa respectively, were used in the calculation of theoretical $\mathrm{Tg}$ values. The $\mathrm{Tgs}$ of the composites were found to deviate positively from the GT predicted values.

Figure 4: Glass transition temperatures of ST: STNa systems as a function of STNa content (squared markers). The solid line represents the Tg predictions based on the Gordon-Taylor with Simha-Boyer rule equation.

The Gordon-Taylor equation is widely accepted to predict the Tg of mixtures. The theory affirms that in the ideal mix free volumes are additive and no interaction between the components takes place during mixing (Caron et al., 2011). However, because of the presence of interacting groups in either species, the ST-STNa mixture could, in theory, result in the formation of intermolecular bonds, such as hydrogen or ion-dipole bonding, which should cause an increase in Tg compared to the predicted values. Tong and Zografi also showed positive deviations of $\mathrm{Tg}$ from GT predicted values when indomethacin was co-processed with its corresponding sodium salt, suggesting a stronger acid-salt interaction in the amorphous state than that between acid-acid and salt-salt (Tong and Zografi, 2001).

FTIR spectroscopy has been used to investigate molecular interaction between species, included in composites (Caron et al., 2011; Tong and Zografi, 2001). FTIR spectra (1800-1000 $\mathrm{cm}^{-1}$ ) of spray dried ST, STNa and ST mixed in different proportions with STNa are shown in Fig. 5A. 
Figure 5A: FTIR spectrum in the $1800-1000 \mathrm{~cm}^{-1}$ range of a) spray dried ST; b) to f) spray dried ST:STNa in the ratios 9:1, 3:1, 1:3, 15:85 and g) FTIR spectrum of spray dried STNa. 5B: Job plot representation

Peak shifts of different magnitudes were recorded, depending on the STNa content, indicative of interactions between the two species (Caron et al., 2011; Tong and Zografi, 2001). For example, in the $3000-3500 \mathrm{~cm}^{-1}$ region, the $\mathrm{N}-\mathrm{H}_{2}$ asymmetric stretch peak, which in the spectrum of pure amorphous ST appears at $\sim 3462 \mathrm{~cm}^{-1}$, shifted to lower wavenumbers (data not shown). The shift to lower wavenumbers can be due to weakening of the $\mathrm{N}-\mathrm{H}$ bond as a result of a stronger involvement in H-bondings (Kaushal et al., 2008; Tang et al., 2002). The simultaneous shift to higher wavenumbers of the $\mathrm{C}-\mathrm{NH}_{2}$ stretching peak $\left(\sim 1417 \mathrm{~cm}^{-1}\right.$ on the spectrum of ST), confirmed the $\mathrm{NH}_{2}$ group being increasingly involved in H-bonds (Fig. 5A). In the 1000-1600 $\mathrm{cm}^{-1}$ region, shifts to lower wavenumbers were seen for the peaks at 1140 and $1084 \mathrm{~cm}^{-1}$, characteristic of the stretching of both symmetric $\mathrm{SO}_{2}$ and $\mathrm{C}-\mathrm{S}$ peaks (Hu et al., 2010). These shifts to lower wavenumbers suggested the $\mathrm{SO}_{2}$ group as the $\mathrm{H}$-bond acceptor and the development of $\mathrm{N}-\mathrm{H}^{\cdots} \mathrm{O}$ bondings. This type of interaction was previously described to link dimers of ST in polymorph I (Parmar et al., 2007).

The stretching peak shifts of $\mathrm{N}-\mathrm{H}_{2}$ and $\mathrm{C}-\mathrm{S}$ for the different composites were plotted against the mole fraction of STNa to create a Job plot representation (Fig 5B) in order to determine the stoichiometry of the interaction involving $-\mathrm{NH}_{2}$ and $-\mathrm{SO}_{2}$ groups (Likussar and Boltz, 1971). This approach using solid ATR-FTIR was adapted from the study of Osmani et al. (Osmani et al., 2008) who generated a Job plot from FTIR $\mathrm{C}=\mathrm{O}$ band shifting frequency in solution. The STNa molar fraction associated to the maximum of the Job plots, obtained at two wavenumbers, were between 0.6 and 0.7. The ST: STNa molar ratio of 1:2 lies between these two molar fractions. Therefore, from the plot, it appears that one molecule of ST interacted with two 
molecules of STNa. This interaction between ST and STNa could be responsible for the lack of thermal events observed on the DSC thermograms obtained for the ST 4:6 and ST 1:3, as the ST: STNa molar ratio of 1:2 falls between these two composites.

\section{2 iGC and DVS analysis}

iGC was used to more fully investigate the surface of the systems and to assess the possibility of interactions between ST and STNa at the surface of the spray dried particles. Several phenomena of pharmaceutical importance start at the surface, and are critically affected by the surface properties of the substances involved (Buckton and Gill, 2007; Puri et al., 2010). Surface solidliquid interactions for example, besides affecting processes such as dissolution, can have a deep impact on the stability of the solid, powder flow etc., and are, above all, governed by solid surface free energy $\left(\gamma_{s}^{T}\right)$ (Puri et al., 2010). Generally a substance in its amorphous form has a higher $\gamma_{s}^{T}$ than the corresponding crystalline form because of a more random orientation of molecules exposing higher surface energy groups at the particle surface (Brum and Burnett, 2011; Newell et al., 2001a). This $\gamma_{s}^{T}$ differences can have a significant impact on the behaviour of the two solid states (amorphous versus crystalline) upon processing. Differences in the $\gamma_{s}^{T}$ can also be displayed by amorphous samples of the same material obtained with different processing techniques and changes with time due to relaxation can affect the $\gamma_{s}^{T}$ of amorphous material upon storage (Buckton and Gill, 2007).

Figure 6: Total surface free energy for the different weight ratios (ST: STNa) at different \%RH. Statistical analysis compares data obtained at the same RH value. System ST 1:3 was taken as reference of comparison for statistical post-hoc analysis. $* * * \mathbf{P}<0.001$

As a consequence of the development of interactions between the species included in the processed mixtures, variations of the $\gamma_{s}^{T}$ among the various systems would be expected. STNa 
330 and four different composites were analysed by iGC. The $\gamma_{s}^{T}$ values measured for ST 9:1 and ST $3313: 1$ were not significantly different, and were found to be the highest among the systems studied, 332 at $\sim 53 \mathrm{~mJ} / \mathrm{m}^{2}$ (Fig. 6). The increase in STNa content to the ST 1:3 system decreased significantly 333 the $\gamma_{s}^{T}$ values, down to $\sim 41 \mathrm{~mJ} / \mathrm{m}^{2}(\mathrm{P}<0.001)$. Then $\gamma_{s}{ }^{T}$ rose up again for the pure amorphous salt, 334 reaching $\sim 48 \mathrm{~mJ} / \mathrm{m}^{2}$ (Fig. 6). The minimum of ${\gamma_{s}}^{T}$ obtained for ST 1:3 could be due to a different 335 organisation and/or to the development of interactions between the molecules at the surface of 336 the particles, decreasing the number of chemical groups available to interact with external 337 molecules such as the probe molecules. Moreover, changes in ST: STNa ratio also influenced the 338 polarity of the powder surfaces as shown by the variation in the polarity index $\left(\gamma_{S}^{A B} / \gamma_{S}^{d}\right)$ in Fig. $3397 \mathrm{~A}$.

Figure 7: Polarity index (A) and spreading coefficient (B) changes for different weight ratios and \%RH. Statistical analysis compares data obtained at the same RH value. System ST 1:3 was taken as reference of comparison for statistical post-hoc analysis $* * * \mathbf{P}<0.001, * * \mathbf{P}<0.01, * \mathbf{P}<0.05$.

An increase in salt content from ST 9:1 to ST 3:1 raised the polarity index, reaching a value similar to that obtained for pure amorphous STNa. However, a further increase (in salt content) to ST 1:1 and ST 1:3 reduced the surface polarity. The ST: STNa molar ratio 1:2 falls between 347 that of these two systems (i.e. ST 1:1 and ST 1:3), which supports the concept of the 348 development of 1:2 interactions, as previously suggested by FTIR spectroscopy. Therefore, ST349 STNa interaction should involve polar bonding, decreasing the amount of polar chemical groups 350 available at the surface to interact with the probe molecules.

351 Water adsorption is strongly influenced by surface polarity (Bradley et al., 2010). In particular, 352 water vapor molecules can interact with solids through specific hydrogen-bonding with surface 
353 polar groups. Furthermore, when the solid is ionic, water molecules can interact with the 354 components of the solid through ion-dipole interaction. For amorphous solids, the wettability and 355 interaction with water are fundamental aspects to be studied because they can affect both 356 dissolution properties (Puri et al., 2010) and physical stability (Hancock and Zografi, 1994; Puri 357 et al., 2010). Both STNa and ST 1:3 deliquesced when exposed to ambient humidity conditions. 358 Hence, the interaction of the composites with water was investigated by calculating the powder 359 wettability and analysing the water vapor sorption isotherms.

The wettability of a powder by water depends on both the work of adhesion of the water onto the powder surface $\left(W_{A}\right)$ and on the water work of cohesion $\left(W_{C}\right)$. Complete spreading of the water over a powder is possible if the work of adhesion onto the surface is equal to or higher than the work of cohesion among the water molecules (Zdziennicka and Jańczuk, 2010). This difference 364 equals the spreading coefficient $\left(S_{S L}\right)$. The $S_{S L}$ of water over the composites, for various $\%$ RH, is reported in Fig. 7B. For all systems the $S_{S L}$ was negative, indicating that the spreading of water 366 on the powder surface is not favoured and requires work. For each system, $S_{S L}$ was not affected 367 by a change in the $\% \mathrm{RH}$ from $0 \%$ to $20 \%$ but changed depending on the ST: STNa ratio. An 368 increase in salt content from ST 3:1 to ST 1:3 decreased the $S_{S L}$, indicating a decrease in water 369 affinity for the powder surfaces.

370 The overlayed DVS $1^{\text {st }}$ sorption isotherm plots of the systems indicated that the whole/entire 371 water uptake increased with the increase of salt content over the entire RH range (Fig. 8). The 372 mass gain recorded at $90 \% \mathrm{RH}$ was linearly proportional to the STNa content in the composites. 373 The coefficient of determination $\left(\mathrm{r}^{2}\right)$ of the linear fit was 0.99. For instance, spray dried STNa 374 mass uptake was $36 \% \mathrm{w} / \mathrm{w}$ of the dry mass and decreased to $3.6 \% \mathrm{w} / \mathrm{w}$ for ST 9:1. As previous 
375 studies on the hygroscopicity of ST after spray drying indicated that the API had a maximum 376 water uptake of only $0.5 \%$ at $90 \% \mathrm{RH}$ (Bianco et al., 2012), the water uptake for the blends is 377 primarily due to the salt.

378

379 380

381

382

383

384 385

\section{Figure 8 Water sorption isotherms for spray dried systems with different ST: STNa weight ratios.} The kinetic profiles obtained for systems ST 9:1 (Fig. 9A), ST 3:1 and ST 1:1 showed continuous water uptake versus time before reaching equilibrium for each $\%$ RH steps up to $40 \%$ RH. For these systems during the $50 \% \mathrm{RH}$ step an initial mass increase was followed by a decrease in mass. A similar behaviour was also seen for ST 1:3 but the decrease in mass was lower, recorded at a lower $\mathrm{RH}$ and in two steps at $30 \%$ and $40 \% \mathrm{RH}$ (Fig. 9B). A decrease in mass versus time with increasing $\mathrm{RH}$ for amorphous substances corresponds to the crystallisation of the material (Burnett et al., 2006). The mass loss is attributed to water loss due to the reduced hygroscopicity of a new crystalline phase compared to the amorphous form. Therefore the content of salt in the mixtures influenced the RH at which crystallisation took place by promoting the water uptake which acts as a plasticiser for the mixture.

Figure 9 DVS kinetics (A, B, C) and isotherms (A', B', C') of: A-A') spray dried ST 9:1; B-B') spray dried ST 1:3; C-C') spray dried STNa.

In contrast the kinetics for the pure amorphous STNa did not show any mass loss but a continuous increase in mass with increasing RH (Fig. 9C). Generally, crystalline solids with high solubility such as salts may deliquesce at a $\mathrm{RH}$ value lower than $100 \%$, defined as $\mathrm{RH}_{0}$, which is characteristic of the material. $\mathrm{RH}_{0}$ of a compound can be determined from the moisture sorption isotherm as a sharp break due to a sudden change in water uptake which takes place at deliquescence (Hiatt et al., 2011). In contrast, when dealing with amorphous solids, deliquescence can be regarded as a non-equilibrium phase transition because water uptake by 
amorphous substances proceeds in a gradual way and their transformation from solid to liquid state may involve intermediate semi-solid stages (Mikhailov et al., 2009). It was not possible to determine the RH of deliquescence for amorphous STNa either from the water sorption isotherm

401 (Figure 9C) or the corresponding kinetics (Figure 9C').

402 Both ST 1:3 and STNa recorded mass uptake of respectively $\sim 4.3 \%$ and $7 \%$ at the end of the first 403 cycle. The water uptake for amorphous STNa was previously attributed to the crystallisation of 404 the amorphous salt to a sesquihydrate (Bianco et al., 2012). PXRD analysis performed at the end 405 of the water sorption isotherm confirmed that the composites converted to the same 406 sesquihydrate form. Additional mass losses were detected in the kinetics for all composites in the 407 second DVS sorption cycle (Fig. 9). These mass losses were of lower magnitude compared those 408 in the first cycles. These mass losses indicated a not complete (i.e. partial) crystallisation of the 409 amorphous systems at the end of the first sorption cycle. Full crystallisation following exposure 410 to a first full $0-90 \%$ RH cycle was not achieved and this may be attributed to water not 411 completely penetrating the bulk of the composites.

412 If we consider the adsorption process as the only mechanism of interaction between water and 413 the powders, the higher the surface energy, surface polarity and spreading coefficient the greater 414 is the expected water uptake. However, the surface properties measured for the different 415 composites examined did not correlate with the whole water uptake isotherms. The $\gamma_{s}^{T}$ of ST 9:1 416 and ST 3:1 were greater than those of STNa, ST 1:1 and ST 1:3, respectively. Nonetheless, ST $417 \quad$ 9:1 and ST 3:1 were characterised by lower water uptake compared to the other systems. Despite 418 having the lowest $\gamma_{s}^{T}$ profile (Fig. 6) among all systems examined, the water uptake of ST 1:3 419 was the second highest, lower only than STNa. However amorphous materials can either adsorb 420 water, or absorb it in the bulk of the material (Agrawal et al., 2004; Alvarez-Lorenzo et al., 2000; 
421 Bravo-Osuna et al., 2005). Hence, the distribution of water in the different systems was

422 determined by establishing quantitative correlations between equilibrium moisture content and

423 the \%RH using the Young and Nelson equations (Agrawal et al., 2004; Alvarez-Lorenzo et al.,

424 2000; Bravo-Osuna et al., 2005; Tewes et al., 2010). Fitting DVS data with the Young-Nelson

425 equations indicated that the water distribution within the different systems was dependent on the

426 ST:STNa ratio. For ST 9:1, adsorption was the main process of water uptake, as can be

427 confirmed by the high value of the $A$ parameter, compared to the $B$ parameter of the Young-

428 Nelson equations (Fig. 10).

429

430

431

432

433

434

435

436

437

438

439

440

441

442

443

444

Figure 10: Moisture distribution patterns for 1:3 (A) and 3:1 (B) samples obtained by fitting experimental DVS results with the Young and Nelson equations. Estimated A, B, E Young and Nelson parameters and fit correlation coefficient for all the composites investigated are inserted in the chart (A).

It was found that an increase in STNa content increased the proportion of water absorbed, and water sorption for ST 1:1 and ST 1:3 was mainly by absorption. Fig. 10 shows a comparison of the Young and Nelson distribution patterns of water obtained by fitting DVS results for two systems (A) ST 1:3 and (B) ST 3:1 which are characterised respectively by low and high surface free energy. Most of the water uptake by ST 1:3 was absorbed in the bulk while only a minute amount was adsorbed on the surface. In contrast the water uptake for the higher $\gamma_{s}^{T}$ system ST 3:1 was due to both adsorption and absorption. The higher amount of water adsorbed by ST 3:1 compared to ST 1:3 is consistent with the surface profiles for the two different systems.

Therefore the ratio ST:STNa influenced not only the total hygroscopicity but also the water distribution in the different systems and this may have an important impact on the physical stability of the powders. Several authors have attributed the water uptake by amorphous materials mainly to absorption processes (Alvarez-Lorenzo et al., 2000; Bravo-Osuna et al., 
445 2005; Hancock and Shamblin, 1998). However, according to this study the main water sorption 446 mechanism for the system ST 9:1 was by adsorption, with a minimal amount of water absorbed. 


\section{4. Conclusions}

448 This study showed that an extremely unstable amorphous API like sulfathiazole can be protected 449 from crystallisation by co-spray drying it with its corresponding sodium salt form. In particular 450 the addition of just $10 \% \mathrm{w} / \mathrm{w}$ salt was enough to delay the crystallisation of the resulting powder 451 from 1 to 60 days of storage under desiccated conditions. Increasing the proportion of salt in the 452 composite further improved the storage stability; however this was opposed by an increased 453 hygroscopicity. The increased physical stability may be attributed to interactions between the 454 species which cause the shift of Tg to higher temperature. FTIR spectroscopy, iGC and thermal 455 analysis suggested interactions between the species with a stoichiometry of 1 molecule of acid 456 for 2 molecules of salt. For the systems investigated, by analysing the hygroscopic properties it 457 has also emerged that water uptake by an amorphous material could either be mainly by 458 adsorption or by absorption depending on the chemical nature of the material, with the salt 459 facilitating water absorption. Therefore controlling the physico-chemical properties of the 460 composites by varying the ratio of the components can be beneficial to stabilise amorphous 461 formulations. For example among the ST: STNa composites an optimum mixture which 462 provided the best compromise between hygroscopicity and stability was the 1:1 w:w system. In 463 this ratio the amorphous powder was characterised by good physical stability, intermediate water 464 uptake and low surface free energy. 


\section{5. Acknowledgement}

467 This paper is based upon works supported by the Science Foundation Ireland under grant no.

468 07/SRC/B1158, as part of the Solid State Pharmaceutical Cluster (SSPC) and grant no. 469 07/SRC/B1154, as part of the Irish Drug Delivery Network (IDDN).

470 
Agrawal, A., M. , Manek, R., V. , Kolling, W., M., Neau, S., H., 2004. Water distribution studies within microcrystalline cellulose and chitosan using differential scanning calorimetry and dynamic vapor sorption analysis. Journal of Pharmaceutical Sciences 93, 1766-1779. 2005. Role of water in the physical stability of solid dosage formulations. Journal of Pharmaceutical 477 Sciences 94, 2147-2165.

478

479

480

481

482

483

484

485

486

487

488

489

490

491

492

493

494

495

496

497

Alvarez-Lorenzo, C., Gómez-Amoza, J.L., Martínez-Pacheco, R., Souto, C., Concheiro, A., 2000. Interactions between hydroxypropylcelluloses and vapour/liquid water. European Journal of Pharmaceutics and Biopharmaceutics 50, 307-318.

Baird, J.A., Taylor, L.S., 2012. Evaluation of amorphous solid dispersion properties using thermal analysis techniques. Advanced Drug Delivery Reviews 64, 396-421.

Bianco, S., Caron, V., Tajber, L., Corrigan, O.I., Nolan, L., Hu, Y., Healy, A.M., 2012. Modification of the Solid-State Nature of Sulfathiazole and Sulfathiazole Sodium by Spray Drying. AAPS PharmSciTech, 1-14.

Bosma, M., Ten Brinke, G., Ellis, T.S., 1988. Polymer-polymer miscibility and enthalpy relaxations. Macromolecules 21, 1465-1470.

Bradley, R.H., Andreu, A., Cassity, K., Osbeck, S., Andrews, R., Meier, M., Johnston, C., 2010. Dependence of water vapour adsorption on the polarity of the graphene surfaces of multi-wall carbon nanotubes. Adsorption Science and Technology 28, 903-912.

Bravo-Osuna, I., Ferrero, C., Jiménez-Castellanos, M.R., 2005. Water sorption-desorption behaviour of methyl methacrylate-starch copolymers: effect of hydrophobic graft and drying method. European Journal of Pharmaceutics and Biopharmaceutics 59, 537-548.

Brum, J., Burnett, D., 2011. Quantification of surface amorphous content using dispersive surface energy: The concept of effective amorphous surface area. AAPS PharmSciTech 12, 887-892.

Buckton, G., Gill, H., 2007. The importance of surface energetics of powders for drug delivery and the establishment of inverse gas chromatography. Advanced Drug Delivery Reviews 59, 1474-1479.

Burnett, D.J., Thielmann, F., Sokoloski, T., Brum, J., 2006. Investigating the moisture-induced crystallization kinetics of spray-dried lactose. International Journal of Pharmaceutics 313, 23-28.

Caron, V., Tajber, L., Corrigan, O.I., Healy, A.M., 2011. A comparison of spray drying and milling in the production of amorphous dispersions of sulfathiazole/polyvinylpyrrolidone and sulfadimidine/ polyvinylpyrrolidone. Molecular Pharmaceutics 8, 532-542. 
Della Volpe, C., Siboni, S., 1997. Some reflections on acid-base solid surface free energy theories. Journal of Colloid and Interface Science 195, 121-136.

Grossjohann, C., Eccles, K.S., Maguire, A.R., Lawrence, S.E., Tajber, L., Corrigan, O.I., Healy, A.M., 2012. Characterisation, solubility and intrinsic dissolution behaviour of benzamide: Dibenzyl sulfoxide cocrystal. International Journal of Pharmaceutics 422, 24-32.

Hancock, B.C., Shamblin, S.L., 1998. Water vapour sorption by pharmaceutical sugars. Pharmaceutical Science and Technology Today 1, 345-351.

Hancock, B.C., Shamblin, S.L., Zografi, G., 1995. Molecular mobility of amorphous pharmaceutical solids below their glass transition temperatures. Pharmaceutical Research 12, 799-806.

Hancock, B.C., Zografi, G., 1994. The relationship between the glass transition temperature and the water content of amorphous pharmaceutical solids. Pharmaceutical Research 11, 471-477.

Hiatt, A.N., Taylor, L.S., Mauer, L.J., 2011. Effects of co-formulation of amorphous maltodextrin and deliquescent sodium ascorbate on moisture sorption and stability. International Journal of Food Properties 14, 726-740.

Hu, Y., Erxleben, A., Ryder, A.G., McArdle, P., 2010. Quantitative analysis of sulfathiazole polymorphs in ternary mixtures by attenuated total reflectance infrared, near-infrared and Raman spectroscopy. Journal of Pharmaceutical and Biomedical Analysis 53, 412-420.

Kaushal, A.M., Chakraborti, A.K., Bansal, A.K., 2008. FTIR studies on differential intermolecular association in crystalline and amorphous states of structurally related non-steroidal anti-inflammatory drugs. Molecular Pharmaceutics 5, 937-945.

Likussar, W., Boltz, D.F., 1971. Theory of continuous variations plots and a new method for spectrophotometric determination of extraction and formation constants. Analytical Chemistry 43, 1265-1272.

Mikhailov, E., Vlasenko, S., Martin, S.T., Koop, T., Pöschl, U., 2009. Amorphous and crystalline aerosol particles interacting with water vapor: Conceptual framework and experimental evidence for restructuring, phase transitions and kinetic limitations. Atmospheric Chemistry and Physics 9, 94919522.

Newell, H.E., Buckton, G., Butler, D.A., Thielmann, F., Williams, D.R., 2001a. The use of inverse phase gas chromatography to measure the surface energy of crystalline, amorphous, and recently milled lactose. Pharmaceutical Research 18, 662-666.

Newell, H.E., Buckton, G., Butler, D.A., Thielmann, F., Williams, D.R., 2001b. The use of inverse phase gas chromatography to study the change of surface energy of amorphous lactose as a function of relative humidity and the processes of collapse and crystallisation. International Journal of Pharmaceutics 217, 45-56. 
Newman, A.W., Reutzel-Edens, S.M., Zografi, G., 2008. Characterization of the "hygroscopic" properties of active pharmaceutical ingredients. Journal of Pharmaceutical Sciences 97, 1047-1059.

538

539

540

541

542

543

544

545

546

547

548

549

550

551

552

553

554

555

556

557

558

559

560

561

562

563

564

565

566

567

568

Osmani, Q., Hughes, H., Flavin, K., Hedin-Dahlstrom, J., Allender, C.J., Frisby, J., McLoughlin, P., 2008. The use of FTIR and NMR spectroscopies to study prepolymerisation interactions in nitrogen heterocycles. Analytical and Bioanalytical Chemistry 391, 1229-1236.

Parmar, M.M., Khan, O., Seton, L., Ford, J.L., 2007. Polymorph selection with morphology control using solvents. Crystal Growth and Design 7, 1635-1642.

Puri, V., Dantuluri, A.K., Kumar, M., Karar, N., Bansal, A.K., 2010. Wettability and surface chemistry of crystalline and amorphous forms of a poorly water soluble drug. European Journal of Pharmaceutical Sciences 40, 84-93.

Schultz, J., Lavielle, L., Martin, C., 1987. The role of the interface in carbon-fiber epoxy composites. Journal of Adhesion 23, 45-60.

Tajber, L., Corrigan, O.I., Healy, A.M., 2005. Physicochemical evaluation of PVP-thiazide diuretic interactions in co-spray-dried composites - Analysis of glass transition composition relationships. European Journal of Pharmaceutical Sciences 24, 553-563.

Tang, X.C., Pikal, M.J., Taylor, L.S., 2002. A spectroscopic investigation of hydrogen bond patterns in crystalline and amorphous phases in dihydropyridine calcium channel blockers. Pharmaceutical Research 19, 477-483.

Tewes, F., Gobbo, O.L., Amaro, M.I., Tajber, L., Corrigan, O.I., Ehrhardt, C., Healy, A.M., 2011. Evaluation of HP $\beta C D$-PEG microparticles for salmon calcitonin administration via pulmonary delivery. Molecular Pharmaceutics 8, 1887-1898.

Tewes, F., Paluch, K.J., Tajber, L., Gulati, K., Kalantri, D., Ehrhardt, C., Healy, A.M., 2013. Steroid/mucokinetic hybrid nanoporous microparticles for pulmonary drug delivery. European Journal of Pharmaceutics and Biopharmaceutics.

Tewes, F., Tajber, L., Corrigan, O.I., Ehrhardt, C., Healy, A.M., 2010. Development and characterisation of soluble polymeric particles for pulmonary peptide delivery. European Journal of Pharmaceutical Sciences. 41, 337-352.

Tong, P., Taylor, L.S., Zografi, G., 2002. Influence of alkali metal counterions on the glass transition temperature of amorphous indomethacin salts. Pharmaceutical Research 19, 649-654.

Tong, P., Zografi, G., 1999. Solid-state characteristics of amorphous sodium indomethacin relative to its free acid. Pharmaceutical Research 16, 1186-1192.

Tong, P., Zografi, G., 2001. A study of amorphous molecular dispersions of indomethacin and its sodium salt. Journal of Pharmaceutical Sciences 90, 1991-2004. 
569 Van Oss, C.J., Good, R.J., Chaudhury, M.K., 1988. Additive and nonadditive surface tension components 570 and the interpretation of contact angles. Langmuir 4, 884-891.

571 Yu, L., 2001. Amorphous pharmaceutical solids: Preparation, characterization and stabilization. 572 Advanced Drug Delivery Reviews 48, 27-42.

573 Zdziennicka, A., Jańczuk, B., 2010. Behavior of cationic surfactants and short-chain alcohols in mixed 574 surface layers at water-air and polymer-water interfaces with regard to polymer wettability. II. 575 Wettability of polymers. Journal of Colloid and Interface Science 350, 568-576. 


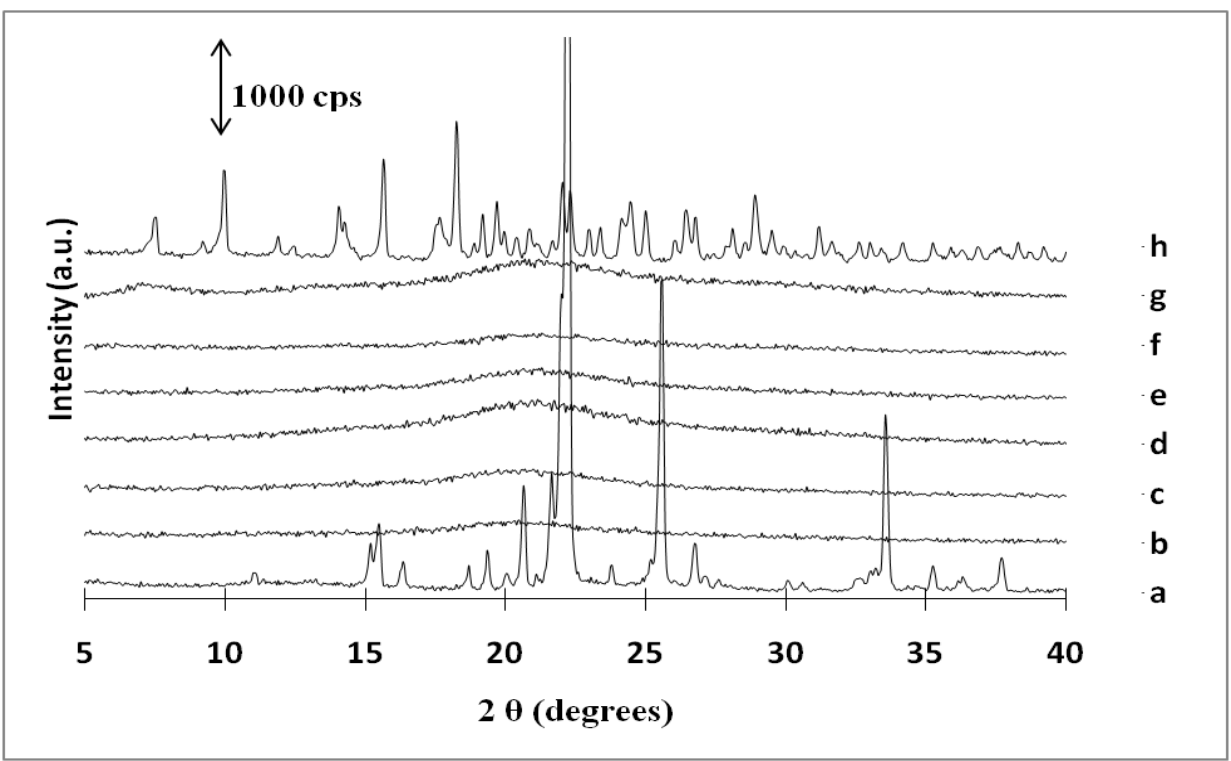

Figure 1: PXRD patterns of: (a) unprocessed ST (form III); b) spray dried ST; c) spray dried ST 9:1; d) spray dried ST 3:1; e) spray dried ST 1:1; f) spray dried ST 1:3; g) spray dried STNa; h) unprocessed STNa. 

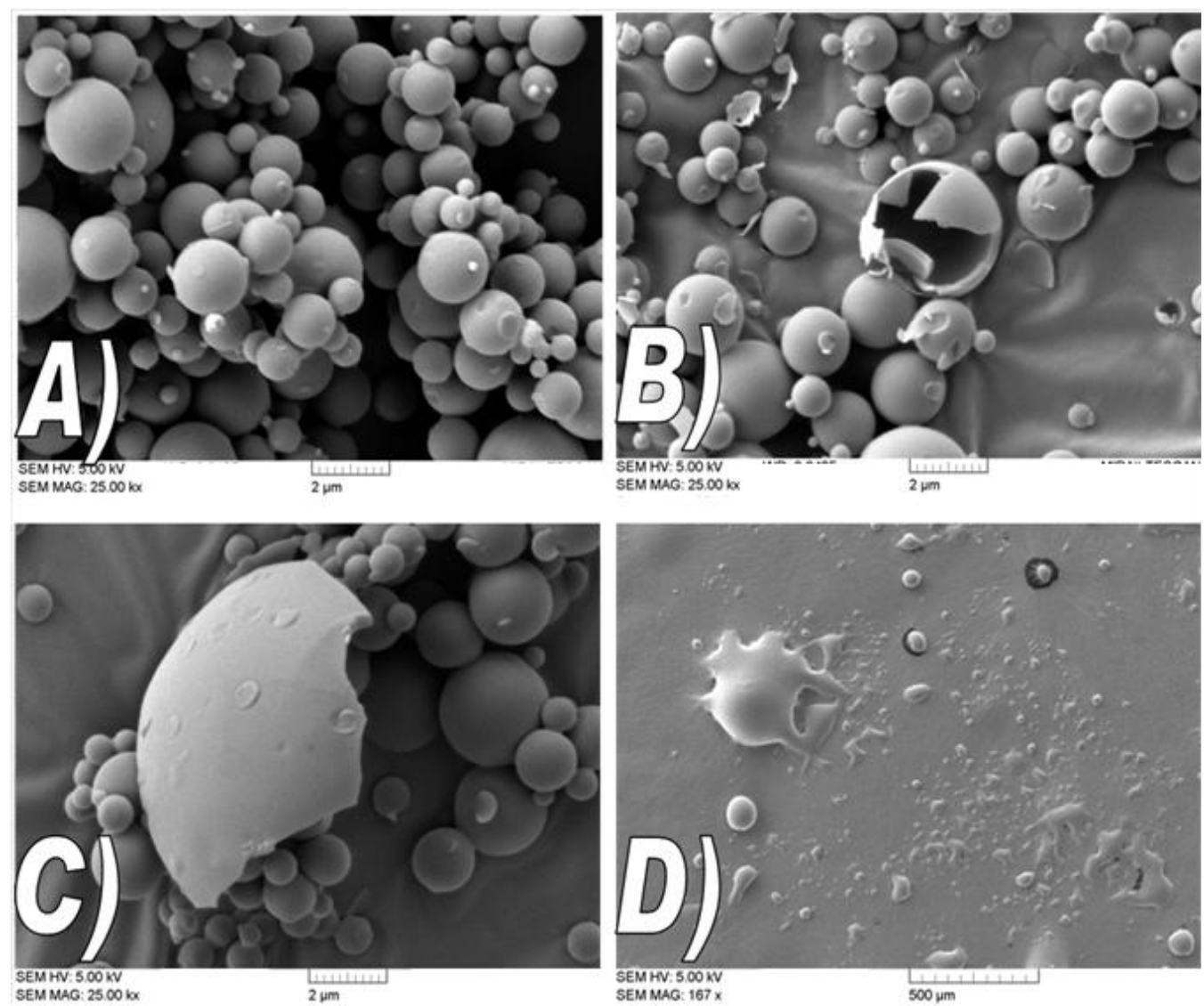

Figure 2: SEM micrographs of: a) spray dried ST 9:1; b) spray dried ST 3:1; c) spray dried ST1:1; d) spray dried ST1:3. 


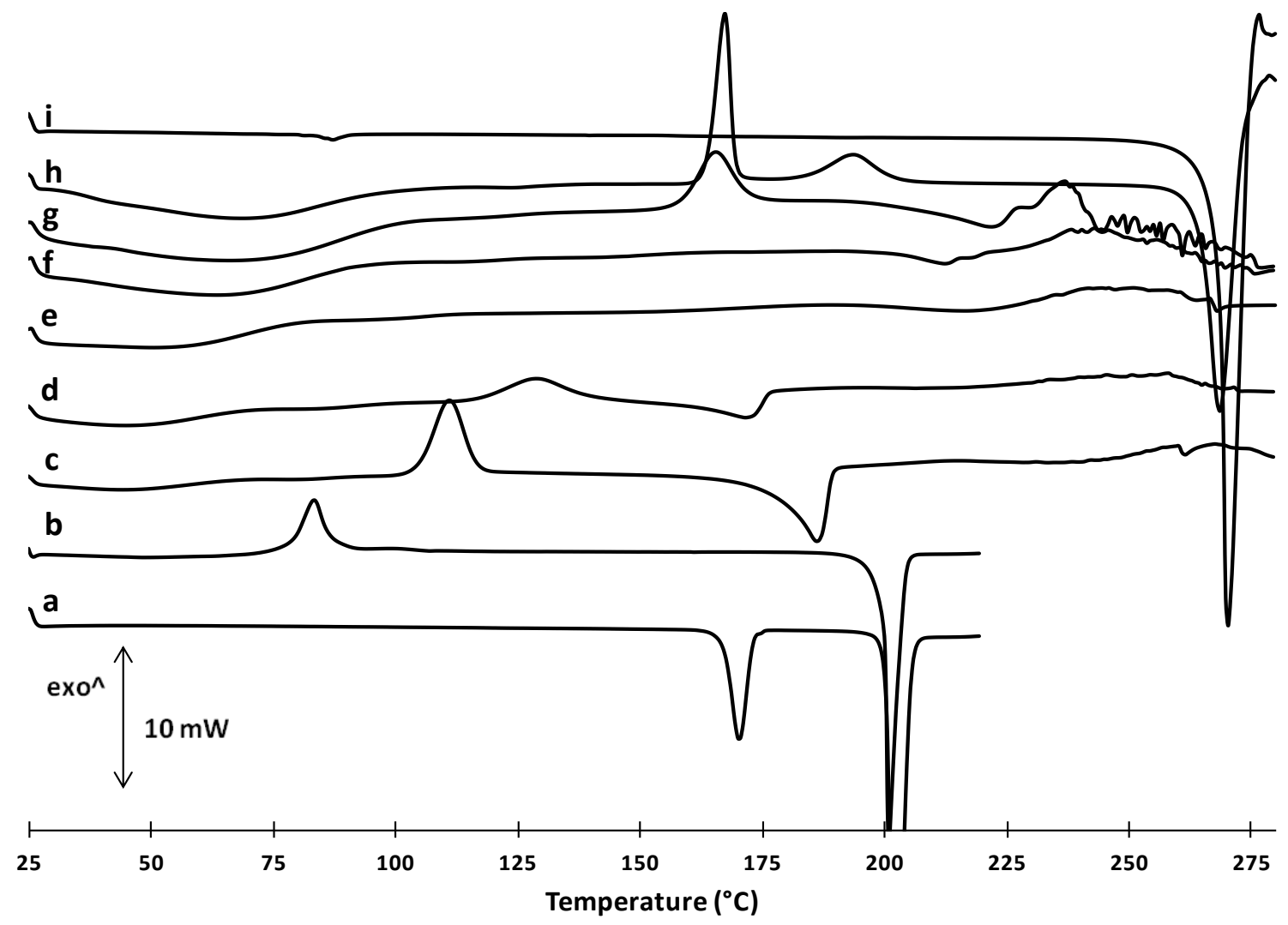

Figure 3 Heat flow thermograms of: (a) unprocessed ST (form III); b) spray dried ST; c) spray dried ST 9:1; d) spray dried ST 3:1; e) spray dried ST 1:1; f) spray dried ST 1:3; g) spray dried ST 15:85 h) spray dried STNa; i) unprocessed STNa. 


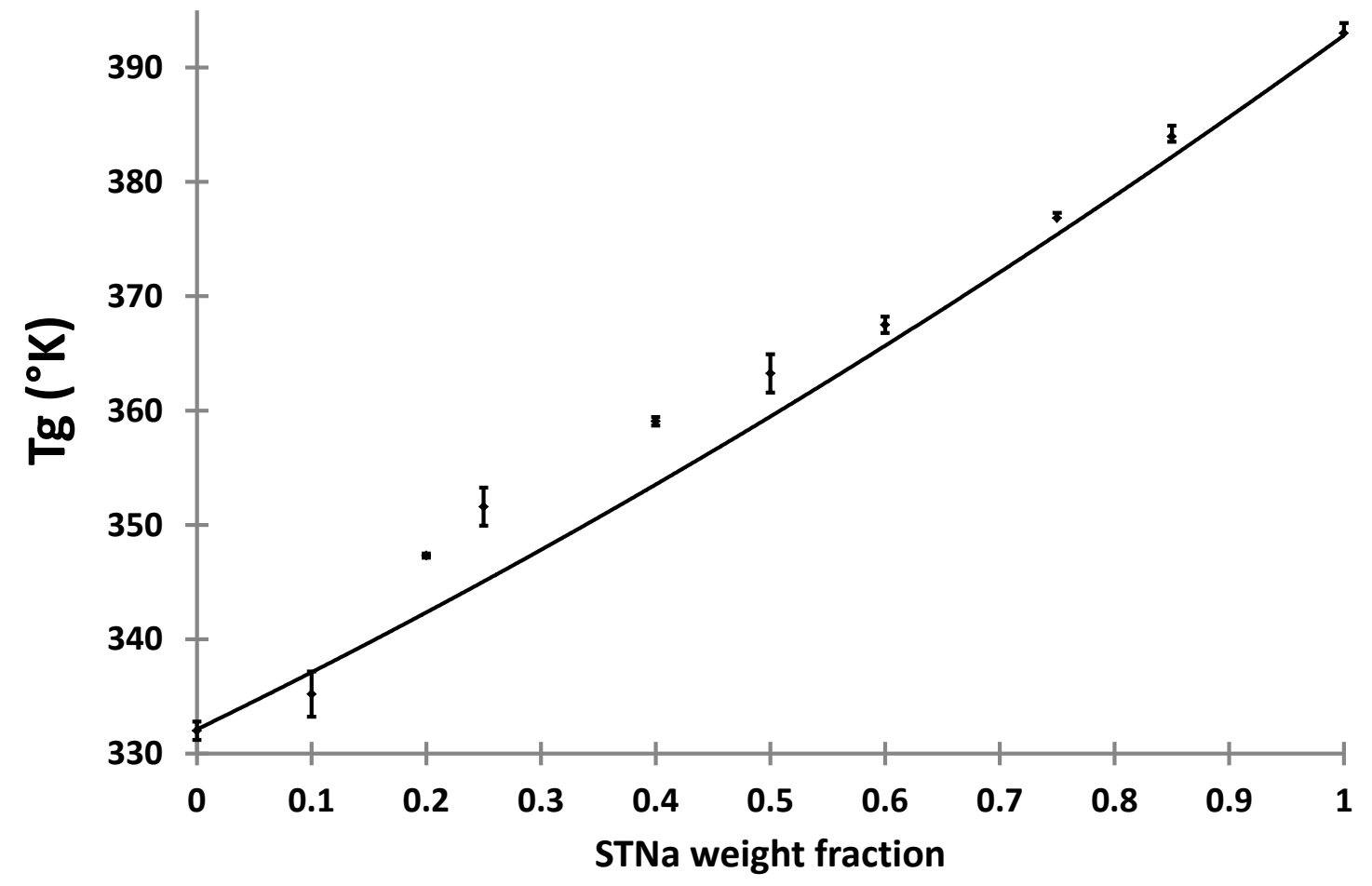

Figure 4: Glass transition temperatures of ST:STNa systems as a function of STNa content (squared markers). The solid line represents the Tg predictions based on the Gordon-Taylor with SimhaBoyer rule equation. 

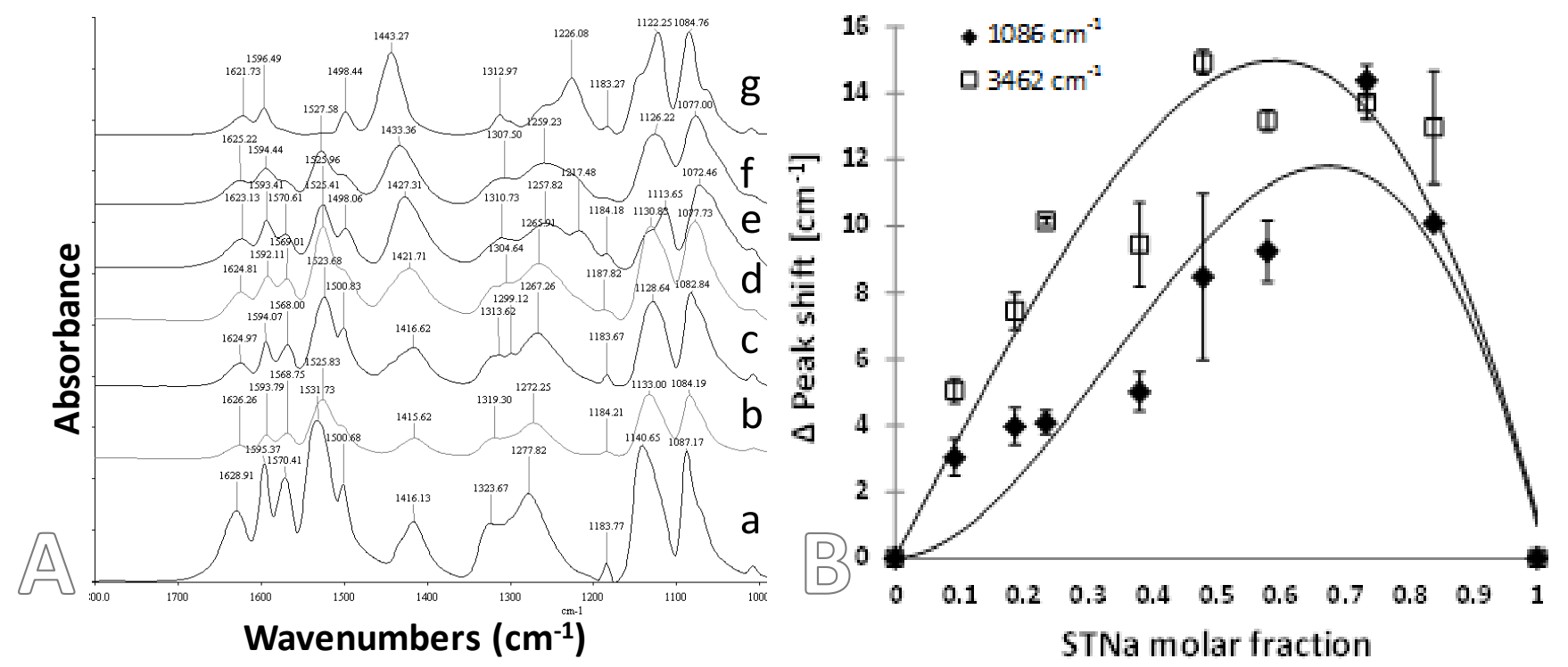

Figure 5A: FTIR spectrum in the $1800-1000 \mathrm{~cm}^{-1}$ range of a) spray dried $\mathrm{ST}$; b) to f) spray dried ST:STNa in the ratios 9:1, 3:1, 1:3, 15:85 and g) FTIR spectrum of spray dried STNa. 5B: Job plot representation 


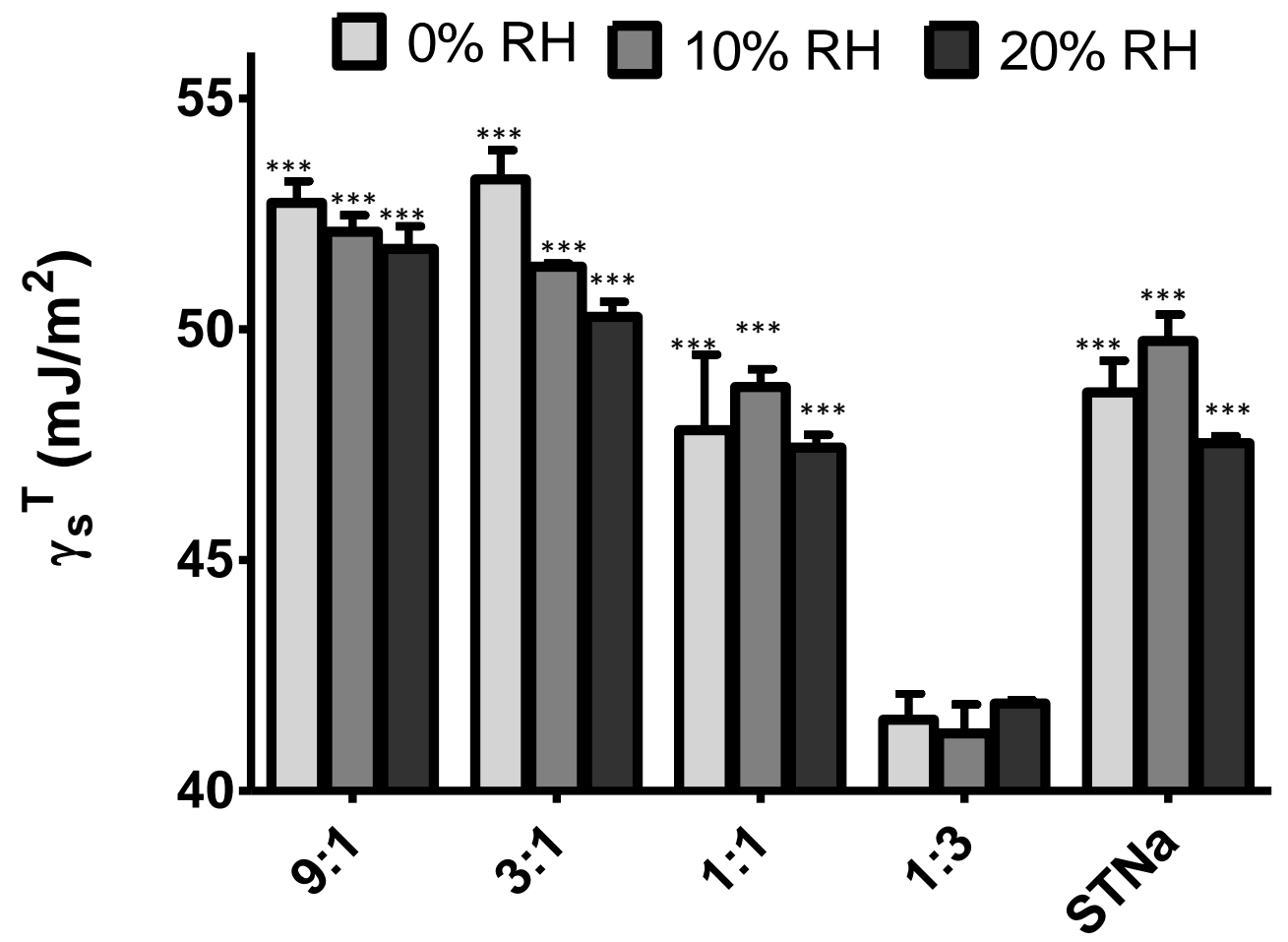

Figure 6: Total surface free energy for the different weight ratios (ST:STNa) at different \% RH. Statistical analysis compares data obtained at the same RH value. System ST 1:3 was taken as reference of comparison for statistical post-hoc analysis. *** $\mathbf{P}<0.001$ 


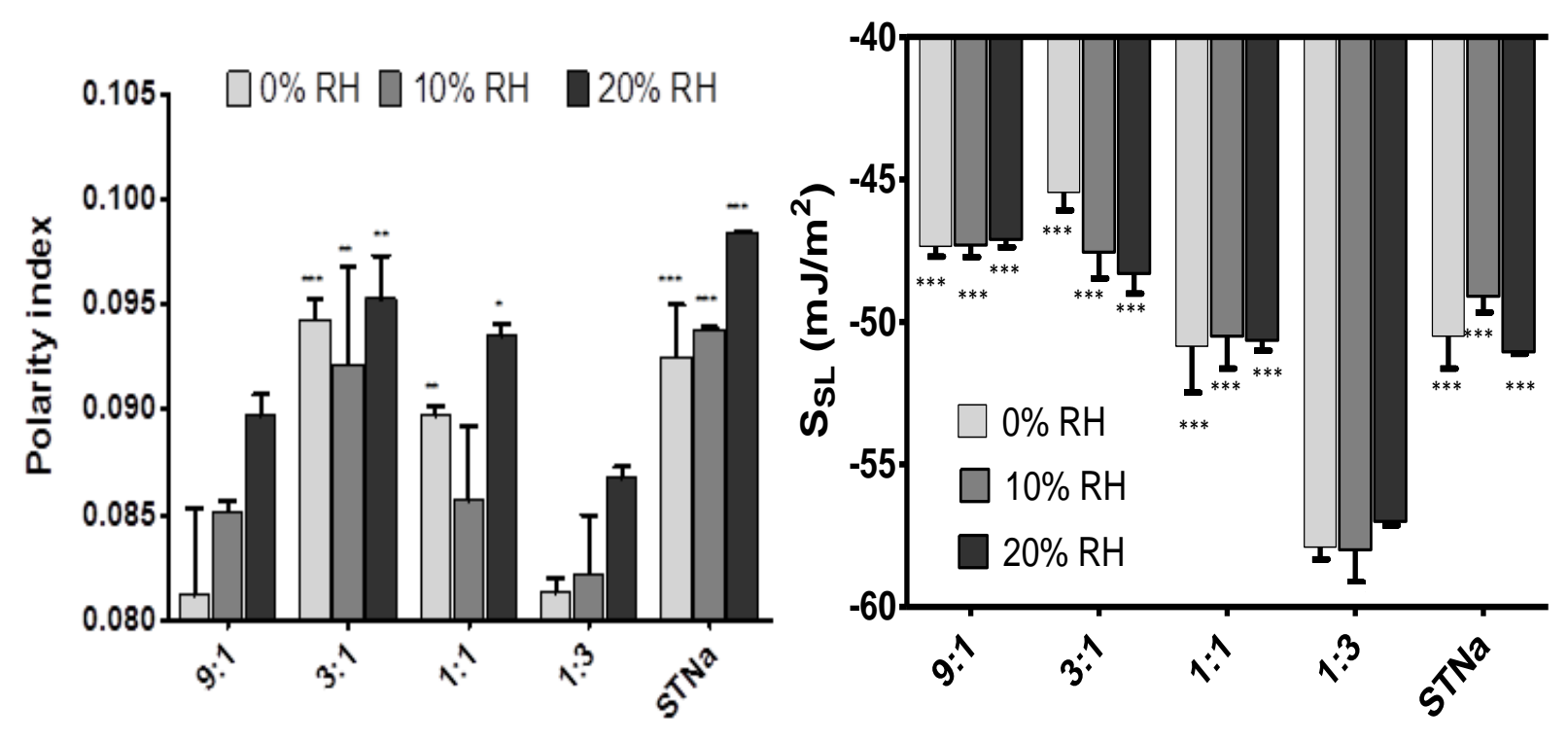

Figure 7: Polarity index (A) and spreading coefficient (B) changes for different weight ratios and \%RH. Statistical analysis compares data obtained at the same RH value. System ST 1:3 was taken as reference of comparison for statistical post-hoc analysis $* * * \mathbf{P}<0.001, * * \mathbf{P}<0.01, * \mathbf{P}<0.05$. 


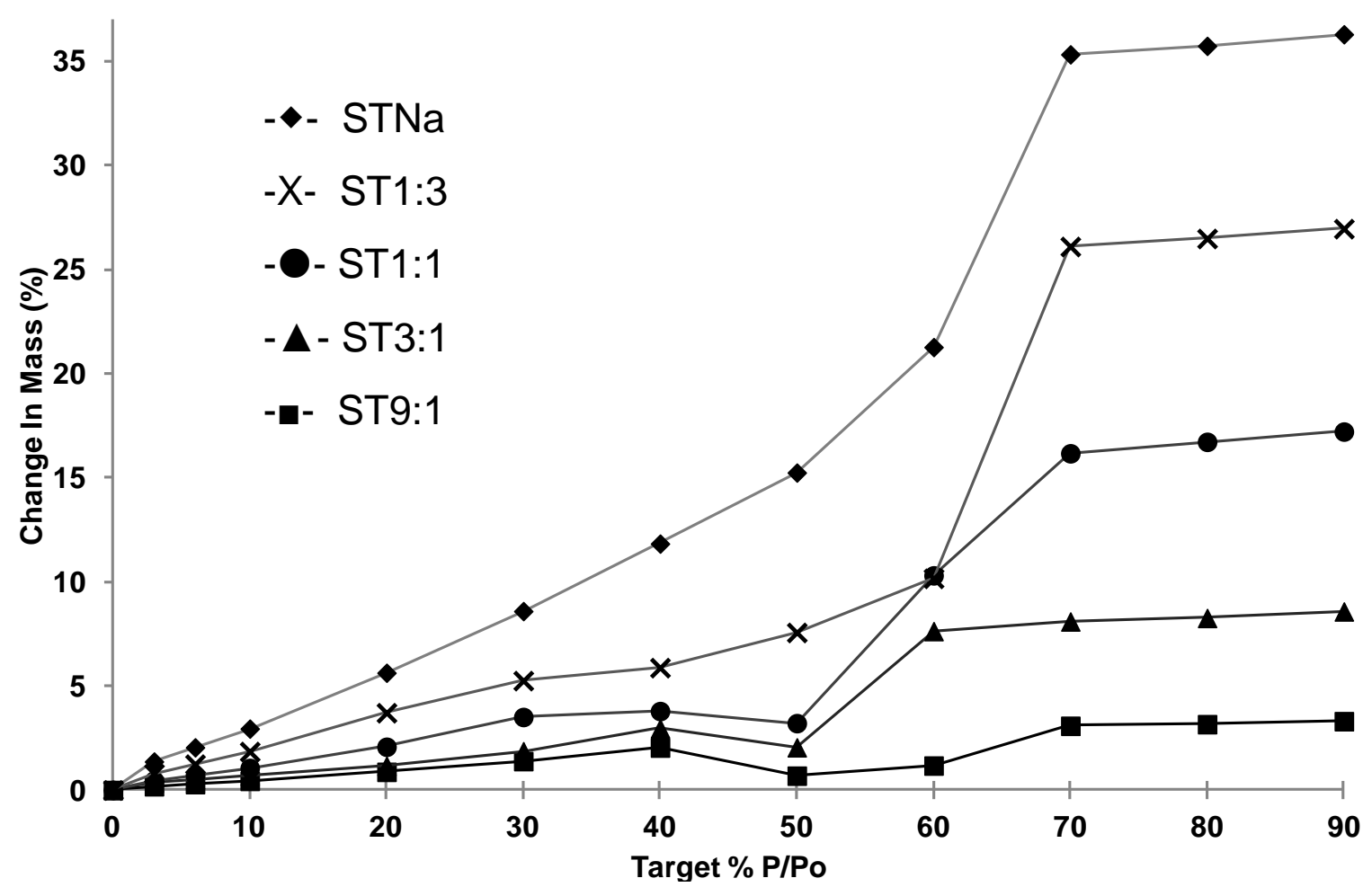

Figure 8: Water sorption isotherms for spray dried systems with different ST:STNa weight ratios. 

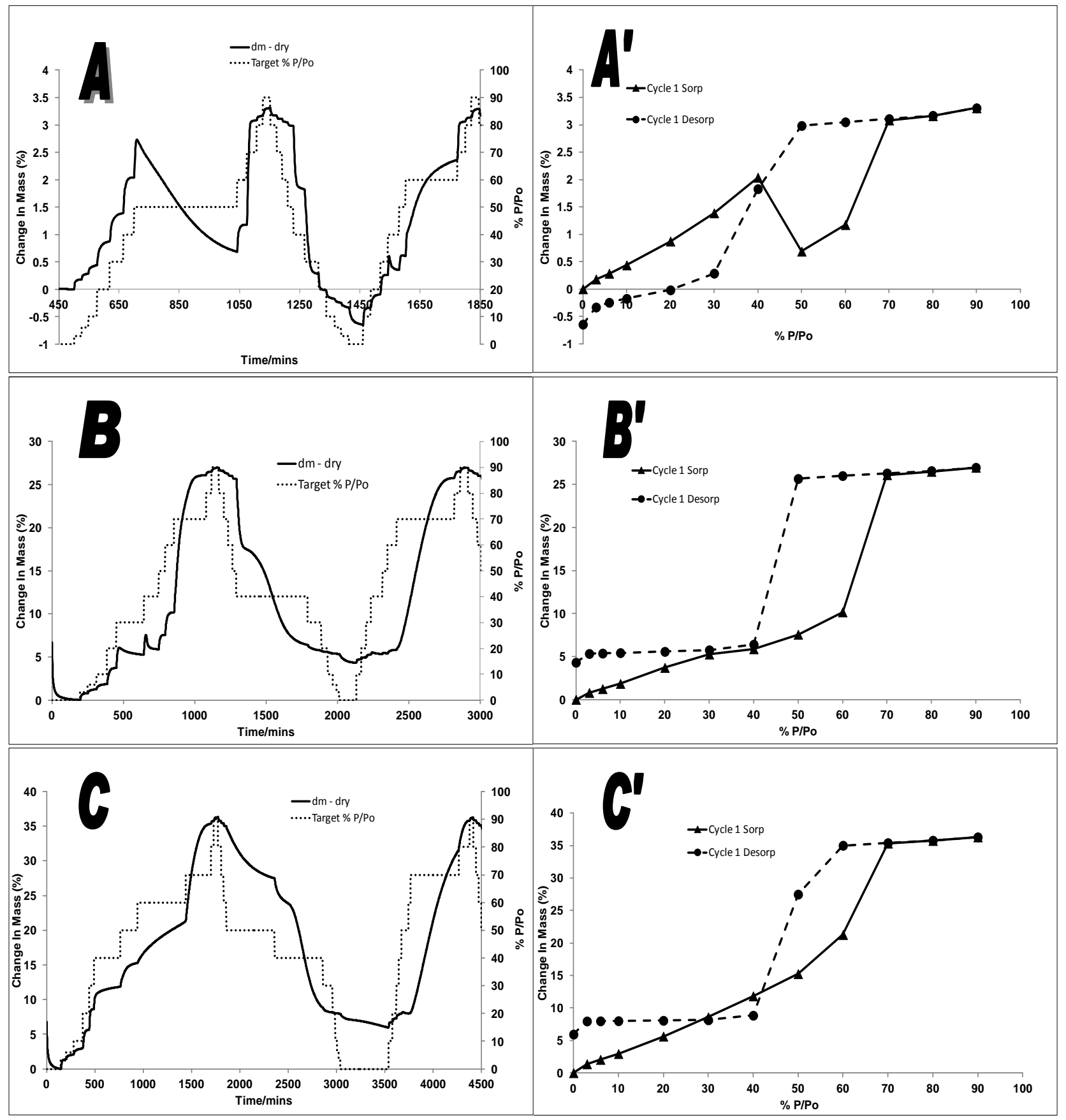

Figure 9 DVS kinetics (A, B, C) and isotherms (A', B', C') of: A-A') spray dried ST 9:1; B-B') spray dried ST 1:3; C-C') spray dried STNa. 

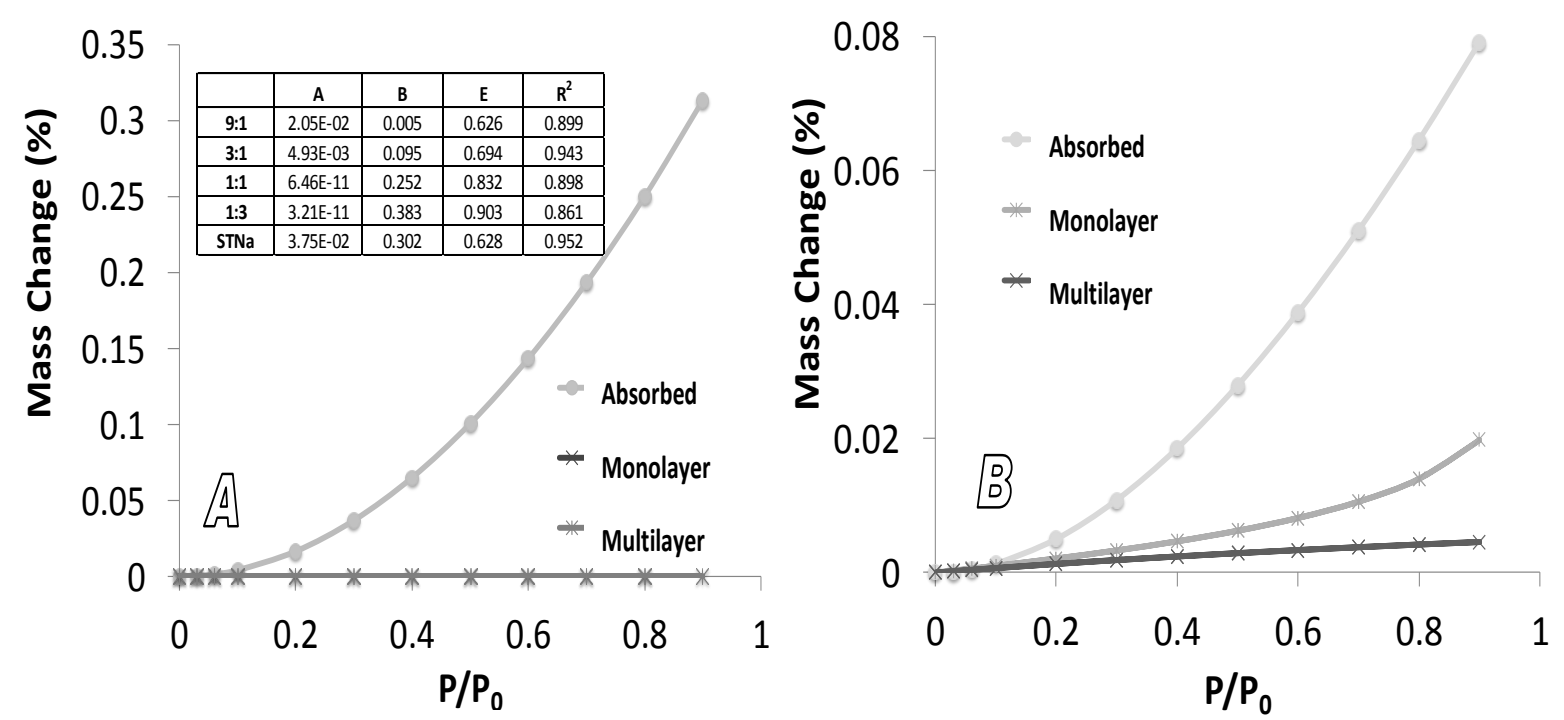

Figure 10: Moisture distribution patterns for 1:3 (A) and 3:1 (B) samples obtained by fitting experimental DVS results with the Young and Nelson equations. Estimated A, B, E Young and Nelson parameters and fit correlation coefficient for all the composites investigated are inserted in the chart (A). 